\title{
Inflammation and the risk of atrial high-rate episodes (AHREs) in patients with cardiac implantable electronic devices
}

\author{
Daniele Pastori ${ }^{1,2} \cdot$ Kazuo Miyazawa $^{1} \cdot$ Yanguang $\mathrm{Li}^{1,3} \cdot$ Farhan Shahid $^{1} \cdot$ Hussein Hado ${ }^{4} \cdot$ Gregory Y. H. Lip $^{1,3,5}$
}

Received: 19 January 2018 / Accepted: 9 April 2018 / Published online: 17 April 2018

(c) The Author(s) 2018

\begin{abstract}
Introduction Atrial high-rate episodes (AHREs) are associated with an increased risk of developing atrial fibrillation and thromboembolism. The characteristics of 'real world' patients developing AHREs are poorly known.

Methods We included 496 consecutive patients with cardiac implantable electronic devices (CIEDs). Primary endpoint was occurrence of AHREs, defined as $>175 \mathrm{bpm}$ and lasting $>5 \mathrm{~min}$, in a median follow-up of 16.5 (IQR 3.9-38.6) months (1082.4 patient-years). We also tested the predictive value of clinical risk scores for AHREs.

Results Mean age was $68.8 \pm 14.0$ years, and 35.5\% were women; AHREs were recorded in 173 patients $[34.7 \%, 16.0 \% /$ year, 95\% confidence interval (CI) 13.7-18.6]. Multivariable Cox regression analysis showed that age [hazard ratio (HR) 1.020, 95\% CI 1.004-1.035, $p=0.011$ ], prior AF (HR 3.521, 95\% CI 2.831-5.206, $p<0.001$ ), white cell count (HR 1.039, 95\% CI $1.007-1.072, p=0.016$ ) and high C reactive protein (CRP; HR 1.039, 95\% CI 1.021-2.056, $p=0.038$ ) were independently associated with AHREs. ROC curve analysis showed that the APPLE score ( $C$ statistic $0.53,95 \%$ CI $0.48-0.59 ; p=0.296)$ ALARMEc score $(C$ statistic $0.51,95 \%$ CI $0.44-0.57 ; p=0.810)$ were non-significantly associated with AHRE. Similar results were obtained for $\mathrm{CHADS}_{2}$ and $\mathrm{CHA}_{2} \mathrm{DS}_{2} \mathrm{VASc}$ score

Conclusion AHREs are common in CIEDs patients, with age, prior AF, inflammatory markers (high CRP, white cell count) being factors associated with AHREs onset. Clinical risk scores showed limited value for AHREs prediction in this cohort.
\end{abstract}

Keywords AHREs $\cdot$ Implantable device $\cdot$ Pacemaker $\cdot$ Atrial fibrillation $\cdot$ Inflammation

Electronic supplementary material The online version of this article (https://doi.org/10.1007/s00392-018-1244-0) contains supplementary material, which is available to authorized users.

Gregory Y. H. Lip

g.y.h.lip@bham.ac.uk

1 Institute of Cardiovascular Sciences, University of Birmingham, Birmingham, UK

2 Department of Internal Medicine and Medical Specialties, I Clinica Medica, Atherothrombosis Center, Sapienza University of Rome, Rome, Italy

3 Department of Cardiology, Chinese PLA Medical School, Chinese PLA General Hospital, Beijing, China

4 Cardiology Department, City Hospital, Birmingham B18 7QH, UK

5 Aalborg Thrombosis Research Unit, Department of Clinical Medicine, Aalborg University, Aalborg, Denmark

\section{Introduction}

Previous studies showed that atrial high-rate episodes (AHREs) are associated with an increased risk of newonset atrial fibrillation (AF) [1], thromboembolism [2-4] and cardiovascular mortality [5]. Subclinical ischaemic brain lesions have also been described in patients with AHREs [6]. However, the thromboembolic risk of AHRE may be lower when compared to patients with $\mathrm{AF}$, and a significant proportion of ischemic strokes recorded in patients with AHREs do not show a significant temporal relationship with AHREs occurrence [7].

Although implicated to play role in cryptogenic stroke, the clinical significance of AHREs is not well understood and the management of these patients is not evidence-based. Furthermore, clinical characteristics and risk factors associated with the development of AHREs are poorly described.

Conventional diagnostic methods, such as resting ECG and Holter monitoring have limited value in the detection of paroxysmal AF and AHREs [8]. Conversely, current use 
of cardiac implanted electronic devices (CIEDs), including pacemakers and implantable defibrillators lead to an improvement in the early detection of atrial and ventricular arrhythmic episodes, especially in patients that are asymptomatic [9]. AHREs lasting $>5 \mathrm{~min}$ are considered as clinically relevant, and patients presenting with AHREs should be assessed for the presence of other risk factors for stroke, and regularly screened to detect overt AF to consider of antithrombotic therapy [10].

We investigated incidence and factors associated with the development of AHREs in a cohort of consecutive patients who underwent CIEDs implantation.

\section{Methods}

We included all consecutive patients with CIEDs including DDD pacemaker, implantable cardioverter defibrillator (ICD), or cardiac resynchronization therapy (CRT) device, who attended the Cardiology Department of Sandwell and West Birmingham Hospitals NHS Trust (Sandwell General Hospital and City Hospital) in Birmingham, United Kingdom from December 2010 to August 2017. We excluded patients with single-chamber VVI devices and patients with $<3$ months of follow-up. The atrial sensitivity was programmed to $0.5 \mathrm{mV}$ with bipolar sensing.

At baseline, personal medical history and information on co-morbidities and concomitant medications were collected. The primary endpoint for the study was the occurrence of AHRE, defined as $>175 \mathrm{bpm}$ and lasting $>5 \mathrm{~min}$. Baseline clinical characteristics of patients with and without AHREs were compared. This study was conducted in accordance with the EU Guidance on Good Clinical Practice CPMP/ $\mathrm{ECH} / 135 / 95$ and the Declaration of Helsinki.

\section{Clinical risk scores}

We tested the predictive value of clinical risk scores in predicting the occurrence of AHREs. The various scores were calculated as follows:

(i) APPLE score: Age [ $>65$ years (A), persistent AF (P), impaired eGFR $\left(<60 \mathrm{ml} / \mathrm{min} / 1.73 \mathrm{~m}^{2}\right)(\mathrm{P}), \mathrm{LA}$ diameter $\geq 43 \mathrm{~mm}(\mathrm{~L})$, and $\mathrm{EF}<50 \%$ (E). Each variable scored 1 point with the score ranging from 0 to 5 points;

(ii) ALARMEc score: AF type (A), Left Atrial size [normalized left atrial area (NLA) $\geq 10.25$ ], Renal insufficiency (eGRF $<68 \mathrm{ml} / \mathrm{min}$ ), Metabolic syndrome and cardiomyopathy (c) with each variable scoring 1 point, and the score values ranging from 0 to 5 points. The ALARMEc score was calculated in a subgroup of 250 patients with complete information on metabolic syndrome. For APPLE and ALARMEc scores left atrial enlargement was calculated as a normalized left atrial volume/body surface area $>28 \mathrm{ml} /$ $\mathrm{m}^{2}$.

(iii) $\mathrm{CHADS}_{2}$ score: congestive heart failure, hypertension, age $\geq 75$, diabetes mellitus, prior stroke or TIA. Each variable was assigned 1 point, prior stroke or TIA was scored 2 points, ranging from 0 to 6 points;

(iv) $\mathrm{CHA}_{2} \mathrm{DS}_{2}$-VASc score: congestive heart failure, hypertension, age $\geq 75$, diabetes mellitus, prior stroke or transient ischemic attack, vascular disease, age 65 to 74 , female; 2 points assigned to age $\geq 75$ and prior stroke or TIA; 1 point to every other variable, ranging from 0 to 9 points.

\section{Statistical analysis}

Continuous variables were expressed as mean \pm standard deviation (SD) or median and interquartile range (IQR), as appropriate. Categorical variables were expressed as numbers and percentages. The Pearson $\chi^{2}$ test was used to compare proportions.

Cox proportional hazards analyses were used to calculate the adjusted relative hazard ratio (HR) by each clinical variable. In the multivariable Cox regression model, only variables with a $p<0.100$ at univariate analysis were entered. Statistical significance was set at a $p$ value $<0.05$.

We also tested the predictive value of clinical risk scores such as APPLE, ALARMEc, $\mathrm{CHADS}_{2}$ and $\mathrm{CHA}_{2} \mathrm{DS}_{2} \mathrm{VASc}$ score. To investigate the predictive performance (expressed as c-indexes) of these scores, we used receiver operating characteristic (ROC) curves, and compared them as described by DeLong et al. [11]. All tests were two-tailed and analyses were performed using computer software packages (IBM SPSS 23.0 for Windows ${ }^{\circledR}$, SPSS Inc.) and MedCalc ${ }^{\circledR}$ V. 18.4.1.

\section{Results}

We included 496 consecutive patients undergoing CIEDs in this study. Indications for CIEDs implantation included sick sinus syndrome (22.2\%), heart block (34.9\%), heart failure (26.3\%), ventricular tachycardia/fibrillation (13.0\%), other ( $2.8 \%$, e.g., recurrent/malignant vasovagal syncope, symptomatic bradycardia), and unknown ( $0.8 \%, 4$ patients).

Mean age was $68.8 \pm 14.0$ years, and $35.5 \%$ were women. Table 1 reports baseline characteristics of patients with and without AHREs. Patients with detected AHREs were older, with a higher prevalence of prior AF (and accordingly, higher use of oral anticoagulants), digoxin use, higher bilirubin and white cell count (Table 1). 
Table 1 Baseline characteristics of patients according to AHREs occurrence

\begin{tabular}{|c|c|c|c|}
\hline & \multicolumn{2}{|c|}{$\operatorname{AHRE}(\geq 5 \mathrm{~min})$} & \multirow[t]{2}{*}{$p$ value } \\
\hline & No $(n=323)$ & Yes $(n=173)$ & \\
\hline Women $(\%)$ & 37.5 & 31.8 & 0.238 \\
\hline Age (years) & $67.9 \pm 14.4$ & $70.3 \pm 13.2$ & 0.078 \\
\hline AF (any type) (\%) & 9.8 & 39.5 & $<0.001$ \\
\hline Paroxysmal AF (\%) & 6.4 & 26.9 & \\
\hline Persistent AF (\%) & 0.6 & 5.3 & \\
\hline Permanent AF (\%) & 2.6 & 7.6 & \\
\hline Hypertension (\%) & 66.8 & 65.3 & 0.763 \\
\hline Diabetes $(\%)$ & 30.1 & 29.1 & 0.837 \\
\hline Heart Failure (\%) & 40.8 & 37.4 & 0.498 \\
\hline CAD $(\%)$ & 41.6 & 36.8 & 0.333 \\
\hline Stroke/TIA (\%) & 9.2 & 12.8 & 0.219 \\
\hline $\begin{array}{l}\text { Metabolic syndrome } \\
(n=250, \%)\end{array}$ & 46.6 & 41.2 & 0.438 \\
\hline $\begin{array}{l}\text { Waist circumference } \\
(n=250, \mathrm{~cm})\end{array}$ & $104.3 \pm 14.7$ & $102.5 \pm 14.8$ & 0.335 \\
\hline LA enlargement $(n=348, \%)$ & 57.4 & 62.9 & 0.368 \\
\hline $\begin{array}{l}\text { Ejection fraction }(n=358, \\
\%)\end{array}$ & $45.4 \pm 18.6$ & $48.4 \pm 16.8$ & 0.119 \\
\hline Haemoglobin (g/l) & $132.3 \pm 18.4$ & $133.3 \pm 18.3$ & 0.573 \\
\hline Platelet count $\left(\times 10^{9} / 1\right)$ & $241.8 \pm 76.6$ & $229.1 \pm 63.6$ & 0.064 \\
\hline White cell count $\left(\times 10^{9} / 1\right)$ & $7.8 \pm 2.4$ & $8.7 \pm 5.7$ & 0.011 \\
\hline CRP (mg/l) & $3.0(2.0-10)$ & $5.0(2.5-11.5)$ & 0.150 \\
\hline $\begin{array}{l}\text { High CRP (above median) } \\
(\%)\end{array}$ & 47.9 & 56.6 & 0.099 \\
\hline Creatinine $(\mu \mathrm{mol} / \mathrm{l})$ & $100.4 \pm 55.0$ & $99.2 \pm 42.7$ & 0.797 \\
\hline eGFR classes & & & 0.480 \\
\hline$>90 \mathrm{ml} / \mathrm{min} / 1.7$ & 18.9 & 16.2 & \\
\hline $89-50 \mathrm{ml} / \mathrm{min} / 1.7$ & 50.9 & 50.3 & \\
\hline 49-30 ml/min/1.7 & 25.5 & 30.6 & \\
\hline$<30 \mathrm{ml} / \mathrm{min} / 1.7$ & 4.7 & 2.9 & \\
\hline $\mathrm{eGFR}<68 \mathrm{ml} / \mathrm{min} / 1.7(\%)$ & 47.5 & 50.3 & 0.572 \\
\hline $\mathrm{eGFR}<60 \mathrm{ml} / \mathrm{min} / 1.7(\%)$ & 30.2 & 33.5 & 0.477 \\
\hline ALT (U/l) & $28.2 \pm 25.9$ & $29.0 \pm 32.0$ & 0.786 \\
\hline Potassium (mmol/l) & $4.6 \pm 2.4$ & $4.5 \pm 0.5$ & 0.460 \\
\hline Bilirubin $(\mu \mathrm{mol} / \mathrm{l})$ & $11.7 \pm 6.8$ & $13.0 \pm 9.9$ & 0.048 \\
\hline Beta Blockers (\%) & 40.2 & 42.4 & 0.699 \\
\hline ACEI/ARB (\%) & 57.0 & 57.6 & 0.924 \\
\hline Diuretic (\%) & 43.4 & 50.0 & 0.181 \\
\hline Oral anticoagulant $(\%)$ & 13.0 & 36.8 & $<0.001$ \\
\hline Antiplatelet (\%) & 49.4 & 40.4 & 0.058 \\
\hline Digoxin (\%) & 3.8 & 11.8 & 0.002 \\
\hline Amiodarone (\%) & 8.9 & 9.4 & 0.869 \\
\hline Statin $(\%)$ & 63.0 & 62.4 & 0.922 \\
\hline Calcium channel blocker (\%) & 19.9 & 18.2 & 0.718 \\
\hline
\end{tabular}

$A C E I$ angiotensin-converting enzyme inhibitor, $A R B$ angiotensin receptor blocker, $A F$ atrial fibrillation, $A L T$ alanine aminotransferase, $C A D$ coronary artery disease (previous myocardial infarction, cardiac revascularization), $C R P$ C reactive protein, $e G F R$ estimated glomerular filtration rate, $L A$ left atrium, TIA transient ischaemic attack

\section{Predictors of AHREs}

28 patients with missing data at follow-up were excluded from this analysis. Hence, 471 CIEDs patients were included in the Cox regression model. Overall, 173 AHREs (34.7\%) were recorded during a median follow-up of 16.5 (IQR 3.9-38.6) months yielding 1082.4 patient-years of observation (incidence rate 16.0\%/year, 95\% CI 13.7-18.6).

Based on results from univariate Cox regression analysis (Table 2), age, atrial fibrillation, stroke/TIA, white cell count, bilirubin, diuretic, antiplatelet, and digoxin were used as covariates in the multivariable model. The variable "oral anticoagulation" was excluded from the final model as $>90 \%$ of these patients were already classified as "having AF". However, in a fully adjusted model "oral anticoagulation" was not significant, and this exclusion did not modify final results (data not shown). The multivariable Cox regression analysis showed that age [hazard ratio (HR) 1.020, 95\% CI $1.004-1.035, p=0.011$ ], prior AF (HR 3.521, 95\% CI 2.831-5.206, $p<0.001$ ), white cell count (HR 1.039, 95\% CI 1.007-1.072, $p=0.016$ ) and high CRP (above median, HR $1.039,95 \%$ CI $1.021-2.056, p=0.038$ ) were independently associated with AHREs onset (Table 2).

\section{Clinical risk scores for AHREs}

Clinical risk scores showed only modest and statistically non-significant predictive ability for AHREs. ROC curves for each score are shown in supplementary Fig. 1. The APPLE Score was tested on 348 patients with 132 AHREs, and had a $C$ statistic of 0.53 (95\% CI 0.48-0.59) $p=0.296$. The ALARMEc score was tested on 233 patients with 93 incident AHREs and a $C$ statistic of 0.51 (95\% CI 0.44-0.57) $p=0.810$. In this subgroup where metabolic syndrome could be defined, the $\mathrm{C}$ statistics for the APPLE score was 0.56, 95\% CI 0.50-0.63; $p=0.054$. Similar non-significant results were obtained for $\mathrm{CHADS}_{2}$ and $\mathrm{CHA}_{2} \mathrm{DS}_{2} \mathrm{VASc}_{2}$ scores (see supplementary Fig. 1).

\section{Discussion}

The main findings of this 'real world' cohort study are as follows: (1) more than $30 \%$ of CIEDs recipients have devicedetected AHREs, (2) presence of AF, older age, high CRP and white cell count all independently predicted incident AHREs, and (3) clinical risk scores have generally limited value for AHREs prediction.

The reported incidence of AHRE in previous studies ranges from 30 to $70 \%$ according to different definitions used [2]. Some studies defined AHRE by a rate between 170 and $225 \mathrm{bpm}$, with the duration of the episode $>20 \mathrm{~s}$ or $>5-6$ min [12]. In our cohort, $34.6 \%$ of patients had a 
Table 2 Cox regression analysis for AHREs predictors

\begin{tabular}{|c|c|c|c|c|c|c|c|c|}
\hline \multirow[b]{3}{*}{ Age } & \multicolumn{4}{|l|}{ Univariate } & \multicolumn{4}{|l|}{ Multivariate } \\
\hline & \multirow{2}{*}{$\begin{array}{l}\text { Hazard ratio } \\
1.023\end{array}$} & \multicolumn{2}{|c|}{$\begin{array}{l}95 \% \text { confi- } \\
\text { dence interval }\end{array}$} & \multirow{2}{*}{$\begin{array}{c}p \text { value } \\
<0.001\end{array}$} & \multirow{2}{*}{$\begin{array}{l}\text { Hazard ratio } \\
1.020\end{array}$} & \multicolumn{2}{|c|}{$\begin{array}{l}95 \% \text { confi- } \\
\text { dence interval }\end{array}$} & \multirow{2}{*}{$\frac{p \text { value }}{0.011}$} \\
\hline & & 1.011 & 1.035 & & & 1.004 & 1.035 & \\
\hline Female sex & 0.860 & 0.620 & 1.194 & 0.369 & & & & \\
\hline Atrial fibrillation & 4.877 & 3.556 & 6.690 & $<0.001$ & 3.521 & 2.831 & 5.206 & $<0.001$ \\
\hline Hypertension & 1.101 & 0.795 & 1.523 & 0.563 & & & & \\
\hline Diabetes & 1.104 & 0.790 & 1.542 & 0.562 & & & & \\
\hline Heart failure & 0.904 & 0.659 & 1.241 & 0.533 & & & & \\
\hline Stroke/TIA & 1.507 & 0.959 & 2.369 & 0.075 & 1.458 & 0.902 & 2.355 & 0.124 \\
\hline Coronary artery disease & 0.885 & 0.645 & 1.215 & 0.450 & & & & \\
\hline Haemoglobin & 0.994 & 0.985 & 1.002 & 0.153 & & & & \\
\hline Platelet count & 0.999 & 0.996 & 1.001 & 0.276 & & & & \\
\hline White cell count & 1.048 & 1.021 & 1.077 & 0.001 & 1.039 & 1.007 & 1.072 & 0.016 \\
\hline High CRP & 1.547 & 1.108 & 2.159 & 0.010 & 1.449 & 1.021 & 2.056 & 0.038 \\
\hline Creatinine & 1.000 & 0.996 & 1.004 & 0.932 & & & & \\
\hline ALT & 0.998 & 0.991 & 1.006 & 0.674 & & & & \\
\hline Potassium & 0.924 & 0.748 & 1.140 & 0.461 & & & & \\
\hline Bilirubin & 1.022 & 1.002 & 1.042 & 0.031 & 1.006 & 0.986 & 1.027 & 0.572 \\
\hline Beta blockers & 1.016 & 0.744 & 1.386 & 0.922 & & & & \\
\hline ACEI/ARB & 1.029 & 0.753 & 1.406 & 0.858 & & & & \\
\hline Diuretic & 1.308 & 0.963 & 1.778 & 0.086 & 0.887 & 0.619 & 1.271 & 0.514 \\
\hline Oral anticoagulation & 3.855 & 2.803 & 5.302 & $<0.001$ & & & & \\
\hline Antiplatelet & 0.688 & 0.504 & 0.940 & 0.019 & 0.783 & 0.539 & 1.137 & 0.199 \\
\hline Digoxin & 2.217 & 1.388 & 3.541 & 0.001 & 1.357 & 0.791 & 2.330 & 0.268 \\
\hline Amiodarone & 0.912 & 0.543 & 1.532 & 0.727 & & & & \\
\hline Statin & 1.019 & 0.741 & 1.402 & 0.906 & & & & \\
\hline Calcium channel blockers & 1.173 & 0.793 & 1.737 & 0.424 & & & & \\
\hline
\end{tabular}

See Table 1 for abbreviations detected AHRE, with an incidence rate of $16.0 \%$ year. This percentage is similar to that observed in the ASSERT study, which included 2580 patients with CIEDs and no history of AF, and demonstrated that the AHREs lasting more than 6 min were found in $34.7 \%$ of the patients over a mean follow-up of 2.5 years [1].

We found that increasing age, AF, high CRP and white blood cell count were all independently associated with AHRE occurrence. While age and the presence of supraventricular arrhythmia, such as AF, have been already described as predictors of AHRE/AF, we - as far as we are aware - are the first to describe association between increased inflammatory markers and incidence of AHREs with a direct association between peri-implantation inflammatory biomarkers (CRP and white cell count) and incidence of AHREs during follow-up.

Similarly, a previous study has shown that high postcardiac surgery white cell count was associated with an increased risk of post-operative AF [13]. This finding reinforces the association between inflammation and the occurrence/recurrence of atrial arrhythmia and may represent a common pathogenetic pathway linking AHREs to AF [14]. Thus, upon activation, white cells produce a number of inflammatory mediators, such as cytokines and reactive oxidant species, which interact with cardiomyocytes of atrial tissue leading to electrical remodelling and fibrosis development [15]. The presence of AHREs may represent an early manifestation of this (pro-inflammatory) process.

Moreover, inflammatory mediators favour to a pro-thrombotic state [16, 17], which may account for the increased risk of thromboembolism and cardiovascular mortality also in this setting. Hence, the relationship between inflammation and cardiovascular events in patients with AHREs deserves further research.

Interestingly, we found no significant association between anti-arrhythmic drugs, such as amiodarone, beta blockers or digoxin, and AHRE incidence. This result suggests that the optimal management of patients with AHREs is still to find, and further research is needed to optimize anti-arrhythmic therapy to minimize the burden of silent arrhythmic episodes. 
Several clinical risk scores have been proposed to predict new-onset atrial tachyarrhythmias [18]. However, most were done on small cohorts and had no certain external validation. In our cohort, we tested two of these scores, namely the APPLE and ALARMEc scores, and our results suggest that both have limited predictive value.

The coexistence of prior AF in up to $40 \%$ of patients developing AHRE indicates the close link between the two conditions, representing the clinical continuum of atrial tachyarrhythmias. This may support the need for stroke prevention in patients with AHREs which is currently under evaluation in randomized control trials; two ongoing trials are exploring this issue $[19,20]$. Apart from CIEDs, increasingly sophisticated means of monitoring (e.g., implanted loop recorders) to detect AHREs in various clinical settings and high-risk groups, that would merit consideration of stroke prevention, have been recently investigated [21-23]. Of note, a recent consensus document from the European Heart Rhythm Association recommended that patients presenting with subclinical atrial tachyarrhythmias (i.e., AHRE $>5 \mathrm{~min}$ ) should be considered for oral anticoagulation when $\geq 2$ stroke risk factors using the $\mathrm{CHA}_{2} \mathrm{DS}_{2}$-VASc score are present [24].

\section{Limitations}

The study has some limitations. This was a single-centre study performed in hospital-based setting. As the atrial amplitude during AF decreases, the incidence of AHRE may be underestimated, leading to missed AHRE or to separate a long AHRE episode into multiple brief episodes. Additionally, we did not store all electrogram of AHREs, but device diagnostic information on AHREs was reviewed by at least one experienced electrophysiologist whether they were true AHREs or other device-oversensing events, blinded to clinical outcomes.

In conclusion, AHREs are common in CIEDs patients, with age, prior AF and inflammatory indexes (high CRP, white cell count) being factors associated with AHREs onset. Clinical risk scores showed limited value for AHREs prediction in this cohort.

Funding None directly related to this manuscript.

\section{Compliance with ethical standards}

Conflict of interest None directly related to this manuscript.

Open Access This article is distributed under the terms of the Creative Commons Attribution 4.0 International License (http://creativeco mmons.org/licenses/by/4.0/), which permits unrestricted use, distribution, and reproduction in any medium, provided you give appropriate credit to the original author(s) and the source, provide a link to the Creative Commons license, and indicate if changes were made.

\section{References}

1. Healey JS, Connolly SJ, Gold MR, Israel CW, Van Gelder IC, Capucci A, Lau CP, Fain E, Yang S, Bailleul C, Morillo CA, Carlson M, Themeles E, Kaufman ES, Hohnloser SH, Investigators A (2012) Subclinical atrial fibrillation and the risk of stroke. N Engl J Med 366(2):120-129. https://doi.org/10.1056/ NEJMoa1105575

2. Freedman B, Boriani G, Glotzer TV, Healey JS, Kirchhof P, Potpara TS (2017) Management of atrial high-rate episodes detected by cardiac implanted electronic devices. Nat Rev Cardiol 14(12):701-714. https://doi.org/10.1038/nrcardio.2017.94

3. Camm AJ, Simantirakis E, Goette A, Lip GY, Vardas P, Calvert M, Chlouverakis G, Diener HC, Kirchhof P (2017) Atrial high-rate episodes and stroke prevention. Europace Eur Pacing Arrhythm Card Electrophysiol J Work Groups Card Pacing Arrhythm Card Cell Electrophysiol Eur Soc Cardiol 19(2):169179. https://doi.org/10.1093/europace/euw279

4. Boriani G, Glotzer TV, Santini M, West TM, De Melis M, Sepsi M, Gasparini M, Lewalter T, Camm JA, Singer DE (2014) Device-detected atrial fibrillation and risk for stroke: an analysis of $>10,000$ patients from the SOS AF project (Stroke preventiOn Strategies based on Atrial Fibrillation information from implanted devices). Eur Heart J 35(8):508-516. https:// doi.org/10.1093/eurheartj/eht491

5. Gonzalez M, Keating RJ, Markowitz SM, Liu CF, Thomas G, Ip JE, Lerman BB, Cheung JW (2014) Newly detected atrial high rate episodes predict long-term mortality outcomes in patients with permanent pacemakers. Heart Rhythm Off J Heart Rhythm Soc 11(12):2214-2221. https://doi.org/10.1016/j.hrthm .2014.08.019

6. Benezet-Mazuecos J, Rubio JM, Cortes M, Iglesias JA, Calle S, de la Vieja JJ, Quinones MA, Sanchez-Borque P, de la Cruz E, Espejo A, Farre J (2015) Silent ischaemic brain lesions related to atrial high rate episodes in patients with cardiac implantable electronic devices. Europace Eur Pacing Arrhythm Card Electrophysiol J Work Groups Card Pacing Arrhythm Card Cell Electrophysiol Eur Soc Cardiol 17(3):364-369. https:// doi.org/10.1093/europace/euu267

7. Witt CT, Kronborg MB, Nohr EA, Mortensen PT, Gerdes C, Nielsen JC (2015) Early detection of atrial high rate episodes predicts atrial fibrillation and thromboembolic events in patients with cardiac resynchronization therapy. Heart Rhythm Off J Heart Rhythm Soc 12(12):2368-2375. https://doi.org/10.1016/j. hrthm.2015.07.007

8. Schaer BA, Zellweger MJ, Cron TA, Kaiser CA, Osswald S (2004) Value of routine holter monitoring for the detection of paroxysmal atrial fibrillation in patients with cerebral ischemic events. Stroke J Cereb Circ 35(3):e68-e70. https://doi. org/10.1161/01.STR.0000117568.07678.4B

9. Muller P, Ivanov V, Kara K, Klein-Wiele O, Forkmann M, Piorkowski C, Blockhaus C, Dimitroulis D, Afzal S, Shin DI, Kelm M, Makimoto H, Mugge A (2017) Total atrial conduction time to predict occult atrial fibrillation after cryptogenic stroke. Clin Res Cardiol Off J Ger Card Soc 106(2):113-119. https:// doi.org/10.1007/s00392-016-1029-2

10. Kirchhof P, Benussi S, Kotecha D, Ahlsson A, Atar D, Casadei B, Castella M, Diener HC, Heidbuchel H, Hendriks J, Hindricks G, Manolis AS, Oldgren J, Popescu BA, Schotten U, Van Putte B, Vardas P, Authors/Task Force M, Document R (2016) 2016 ESC Guidelines for the management of atrial fibrillation developed in collaboration with EACTS: the Task Force for the management of atrial fibrillation of the European Society of Cardiology (ESC) Developed with the special contribution of the European Heart Rhythm Association (EHRA) of the 
ESCEndorsed by the European Stroke Organisation (ESO). Eur Heart J https://doi.org/10.1093/eurheartj/ehw210

11. DeLong ER, DeLong DM, Clarke-Pearson DL (1988) Comparing the areas under two or more correlated receiver operating characteristic curves: a nonparametric approach. Biometrics 44(3):837-845

12. Miyazawa K, Pastori D, Lip GYH (2018) Quantifying time in atrial fibrillation and the need for anticoagulation. Prog Cardiovasc Dis 60(4-5):537-541. https://doi.org/10.1016/j. pcad.2017.12.002

13. Lamm G, Auer J, Weber T, Berent R, Ng C, Eber B (2006) Postoperative white blood cell count predicts atrial fibrillation after cardiac surgery. J Cardiothorac Vasc Anesth 20(1):51-56. https ://doi.org/10.1053/j.jvca.2005.03.026

14. Friedrichs K, Klinke A, Baldus S (2011) Inflammatory pathways underlying atrial fibrillation. Trends Mol Med 17(10):556-563. https://doi.org/10.1016/j.molmed.2011.05.007

15. Korantzopoulos P, Kolettis TM, Galaris D, Goudevenos JA (2007) The role of oxidative stress in the pathogenesis and perpetuation of atrial fibrillation. Int J Cardiol 115(2):135-143. https://doi. org/10.1016/j.ijcard.2006.04.026

16. Guo Y, Lip GY, Apostolakis S (2012) Inflammation in atrial fibrillation. J Am Coll Cardiol 60(22):2263-2270. https://doi. org/10.1016/j.jacc.2012.04.063

17. Pfluecke C, Tarnowski D, Plichta L, Berndt K, Schumacher P, Ulbrich S, Forkmann M, Christoph M, Poitz DM, Wunderlich C, Strasser RH, Ibrahim K (2016) Monocyte-platelet aggregates and $\mathrm{CD} 11 \mathrm{~b}$ expression as markers for thrombogenicity in atrial fibrillation. Clin Res Cardiol Off J Ger Card Soc 105(4):314-322. https://doi.org/10.1007/s00392-015-0922-4

18. Deng H, Bai Y, Shantsila A, Fauchier L, Potpara TS, Lip GYH (2017) Clinical scores for outcomes of rhythm control or arrhythmia progression in patients with atrial fibrillation: a systematic review. Clin Res Cardiol Off J Ger Card Soc 106(10):813-823. https://doi.org/10.1007/s00392-017-1123-0

19. Kirchhof P, Blank BF, Calvert M, Camm AJ, Chlouverakis G, Diener HC, Goette A, Huening A, Lip GYH, Simantirakis E, Vardas P (2017) Probing oral anticoagulation in patients with atrial high rate episodes: rationale and design of the non-vitamin $\mathrm{K}$ antagonist oral anticoagulants in patients with atrial high rate episodes (NOAH-AFNET 6) trial. Am Heart J 190:12-18. https ://doi.org/10.1016/j.ahj.2017.04.015

20. Lopes RD, Alings M, Connolly SJ, Beresh H, Granger CB, Mazuecos JB, Boriani G, Nielsen JC, Conen D, Hohnloser SH, Mairesse GH, Mabo P, Camm AJ, Healey JS (2017) Rationale and design of the Apixaban for the reduction of thrombo-embolism in patients with device-detected sub-clinical atrial fibrillation (ARTESiA) trial. Am Heart J 189:137-145. https://doi. org/10.1016/j.ahj.2017.04.008

21. Wachter R, Freedman B (2017) The role of atrial fibrillation in patients with an embolic stroke of unknown source (ESUS). Thromb Haemost 117(10):1833-1835. https://doi.org/10.1160/ TH17-08-0592

22. Israel C, Kitsiou A, Kalyani M, Deelawar S, Ejangue LE, Rogalewski A, Hagemeister C, Minnerup J, Schabitz WR (2017) Detection of atrial fibrillation in patients with embolic stroke of undetermined source by prolonged monitoring with implantable loop recorders. Thromb Haemost 117(10):1962-1969. https://doi. org/10.1160/TH17-02-0072

23. Fauchier L, Clementy N, Bisson A, Stamboul K, Ivanes F, Angoulvant D, Babuty D, Lip GY (2017) Prognosis in patients with atrial fibrillation and a presumed "temporary cause" in a community-based cohort study. Clin Res Cardiol Off J Ger Card Soc 106(3):202-210. https://doi.org/10.1007/s00392-016-1040-7

24. Gorenek BC, Bax J, Boriani G, Chen SA, Dagres N, Glotzer TV, Healey JS, Israel CW, Kudaiberdieva G, Levin LA, Lip GYH, Martin D, Okumura K, Svendsen JH, Tse HF, Botto GLC-C., Group ESCSD. (2017) Device-detected subclinical atrial tachyarrhythmias: definition, implications and management—an European Heart Rhythm Association (EHRA) consensus document, endorsed by Heart Rhythm Society (HRS), Asia Pacific Heart Rhythm Society (APHRS) and Sociedad Latinoamericana de Estimulacion Cardiaca y Electrofisiologia (SOLEACE). Europace Eur Pacing Arrhythm Card Electrophysiol J Work Groups Card Pacing Arrhythm Card Cell Electrophysiol Eur Soc Cardiol. 19(9):1556-1578. https://doi.org/10.1093/europace/eux163 